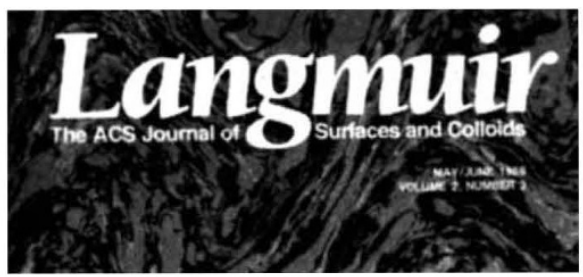

counter the proliferation of specialized journals in surface and colloid chemistry; and secondly to emphasize that this is a broad, important and established field that merits recognition as such. It will complete the coverage by American Chemical Society publications of the main fields of fundamental chemistry, and in addition to articles and letters will publish expert reviews, the Langmuir Award Lectures and book reviews.

Langmuir is to be welcomed as, in effect, the journal of the ACS Division of Colloid and Surface Chemistry, although it also aims to be an international journal, as shown by the world-wide distribution of its advisory board. It will compete with a number of existing journals, some of which already either claim to cover the same field, or have more general scope but publish a substantial proportion of papers on surface and colloid chemistry. These include in the first category commercial journals such as Journal of Colloid and Interface Science, Colloid and Polymer Science, Journal of Dispersion Science and Technology, Colloids and Surfaces and Surface and Colloid Science, and in the second Journal of the Chemical Society, Faraday Transactions I, Berichte der Bunsen Gesellschaft and Journal of Chemical Physics. As intended, it will also draw papers from a wide range of specialist journals.

The first nine issues of Langmuir include many examples of papers which could have been appropriately submitted to one or other of the alternative journals. It is, however, still too early to assess the degree to which it is succeeding in covering its intended field. Most areas are well represented, especially gas-solid systems, surface photochemistry and spectroscopy, insoluble monolayers and electrochemistry. But the coverage of heterogeneous catalysis, as distinct from chemisorption studies, is light, and there are disappointingly few papers on disperse colloids. The quality of the papers is generally high, while the short time to publication, if maintained, will be an attraction to prospective authors.

While one hesitates to approve of yet another new journal, Langmuir undoubtedly has an important role to play in the development of surface and colloid chemistry: indeed, it is a pity that the ACS did not enter the field 20-30 years ago!

Douglas H. Everett is Emeritus Professor in the Department of Physical Chemistry, University of Bristol, Cantock's Close, Bristol BS8 ITS, UK.
Different package deals

\section{J.W. Emsley}

Molecular Crystals and Liquid Crystals: Letters Section. Editor-in-chief M.M. Labes. Gordon \& Breach. 12/yr. UK £106 (corporate), $£ 84$ (institutional), $£ 42.40$ (individual); North America $\$ 128$ (corporate), $\$ 102$ (institutional), $\$ 51.20$ (individual).

Molecular Crystals and Liquid Crystals: Bulletin. Editor-in-chief M. M. Labes. Gordon \& Breach. 12/yr. UK £42 (corporate), £34 (institutional), $£ 16.80$ (individual); North America $\$ 50$ (corporate), $\$ 40$ (institutional), $\$ 20$ (individual).

Bотн of these publications are adjuncts of Molecular Crystals and Liquid Crystals. The Letters used to be published as part of the parent journal, and their issue separately is justified by the editor as a consequence of the increasing number of papers submitted. It is also claimed that there was "a growing interest on the part of subscribers"! To be fair, the editorial does not say which interests of the subscribers were growing, but the implication is that they wanted the Letters to be published separately. I can only comment that I find it hard to believe that many subscribers welcome the fragmentation of a journal, particularly one that involves an increase in cost.

The Letters aim to provide a means of rapid publication, with an average delay of two months, and to achieve this the contributions are produced directly from the authors' camera-ready typescript. The result, inevitably, is considerable variation in the quality of the typography. More importantly, such rapid publication can be achieved only by a reduction in the time spent on refereeing and editing. On the evidence of the issues available to me, the standard of papers is high although very few of them justified rapid publication

The Bulletin contains titles and abstracts of papers to be published in the parent journal and hardly justifies a separate publication. In addition, the intention is to publish the titles of papers given at conferences, and to include news items of interest to the subscribers. This raises the question of to whom these journals are addressed. The stated scope embraces liquid crystals, low-dimensional solids and

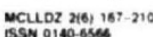

\section{MOLECULAR CRYSTALS AND \\ LIQUID CRYSTALS}

LETTERS SECTION

molecular crystals. In the issues I read the papers on liquid crystals formed a large majority. These materials are the subject of considerable industrial as well as academic attention, and there is undoubtedly a case for a specialized journal dealing with the many different aspects of research and development on them. However, readers interested in liquid crystals will have only a passing interest in either lowdimensional solids or molecular crystals, and certainly those involved in studies of the latter two subjects will find little need for these publications.

J.W. Emsley is a Reader in the Department of Chemistry, University of Southampton, Southampton SO9 $5 \mathrm{NH}, \mathrm{UK}$.

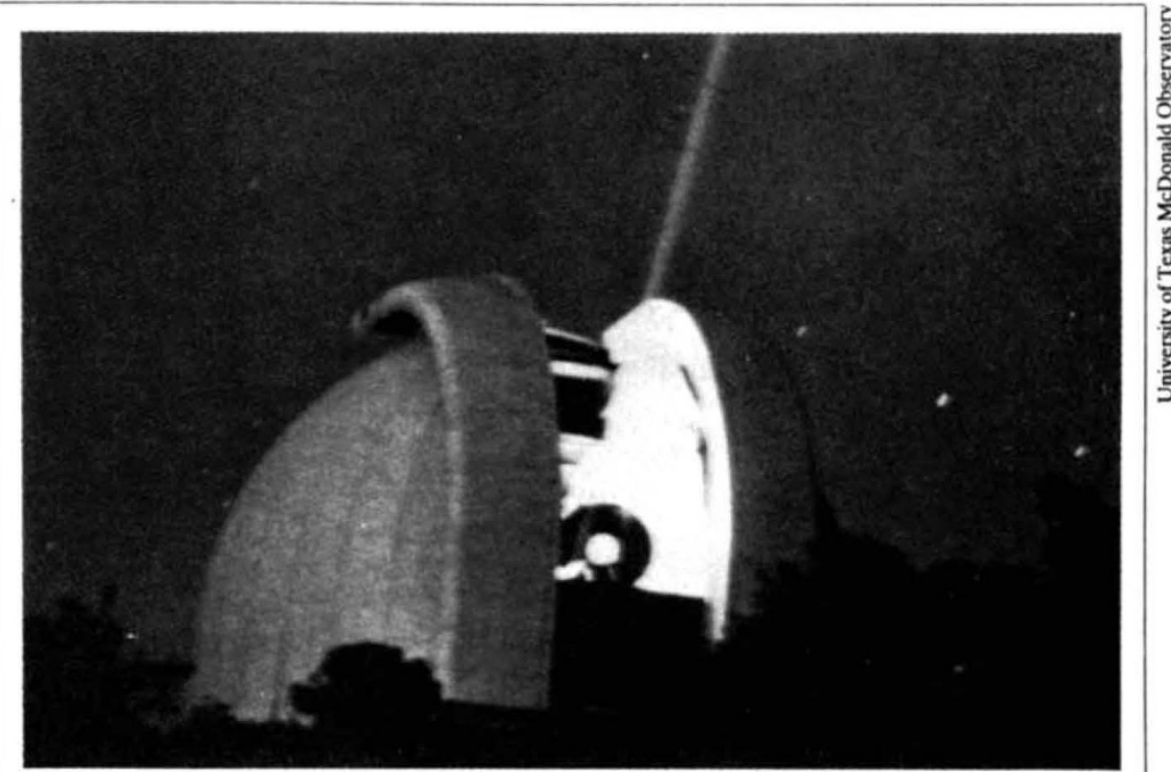

Shooting the Moon - lunar laser-ranging at the University of Texas McDonald Observatory. The illustration is taken from Was Einstein Right? Putting General Relativity to the Test, by Clifford M. Will, to be published next week by Basic Books. The book will be reviewed in Nature's Autumn Books supplement on 13 November. 